\title{
Status displays in automated assembly
}

\author{
D.S. Kochhar and D. Barash \\ Center for Ergonomics, The University of Michigan, Ann Arbor, Michigan, USA
}

The rapid automation of automotive body assembly operations has resulted in a proliferation of the process steps to be monitored and displayed, thereby making the task of the worker more complex. The progression of assembly and associated machine cycling is controlled by programmable logic controllers whose states are displayed on control panels. The significance of the interface between a worker and several panels used in automated assembly is pointed out. Practical problems with the traditional methods of panel design are discussed. The design and layout of select aspects of such control panels are reviewed with examples in reference to six criteria for panel layout.

Keywords: Displays, automation, car manufacture

\section{Introduction}

The automobile industry has maintained an interest in human factors research and applications for many years. This research has predominantly been directed towards improving motor vehicles for passenger comfort, ease of operation and passenger safety.

The manufacturing and assembly processes utilised to make cars have not been subjected to scrutiny by human factors specialists to the same extent as the product. It is possible that passenger and vehicle safety received more research attention because of greater public concern. On the other hand, manufacturing, assembly and other plant operations were specific to a smaller population and were of interest primarily to those directly involved.

With an increase in the need to be competitive, to achieve better product consistency and for cost savings, the automobile industry is being increasingly automated. By removing the human operator from the process loop, routine, repetitive or physically demanding tasks that were previously handled by human operators who could be error prone, inconsistent or erratic, even with training and experience, are assigned to machinery that performs in a co-ordinated, reliable and consistent manner.

Apparently, the benefits of automation and the shortcomings of individual operators seem so clear cut that one might expect to see even more processes become fully automated than is the actual case. But even the most highly sophisticated automated systems or processes cannot handle every contingency; the possibility of system failure is always present. As Rasmussen (1983) points out, the existence of such automated systems depends on extensive support from the human staff to maintain necessary conditions for satisfactory operation and to cope with unforeseen states within the process.
The implication is that a human operator is needed for supervisory monitoring of the equipment and system. In fact, several situations exist where the human must monitor various processes and decide whether and when to direct his or her attention to one of them. As the complexity of such situations increases, more processes of greater variety must be supervised. Thus in order to make the process of automation successful, the interface between the human operator and the automated process should be so designed as to make the operator's task easy to perform. This cautionary note has also been voiced by Margulies and Zemanek (1983) and Bainbridge (1983). In fact, the latter cautions that automation of industrial processes may expand rather than eliminate problems for the human operator, and that human contributions may be more crucial in automated systems than in manual ones.

In the top-down approach to automation, of ten with hierarchical or networked computer control, and programmable controllers for machinery, the need for human intervention is at the system level, most of ten through an operator's terminal. But most physical interaction between humans and machinery occurs at the machine level. This can manifest as manual loading or unloading of parts, or operation of controls for machine set-up or other adjustments. In highly automated plants, such interfaces can be designed by utilising the principles of ergonomics in their design and layout, and in integrating humans to work more efficiently with automated machinery.

\footnotetext{
Automotive assembly

In motor car assembly, some operations are designed so that normal operation is automatic, whereas start-up, shutdown and abnormal conditions are handled manually. Much of the mechanical and process activity is controlled by one or more logical controllers. This can be a mainframe
} 
computer, such as that required for plant performance analysis, or it may be a programmable logic circuit (PLC) for machine control and monitoring. Many assembly operations such as weld quality, fastener torque, wheel camber and caster set, or electrical system operation, are monitored by electrical devices. For example, proximity switches are used to check for positive clamping, contact probes are used to check for location of weld points, and part presence is detected by trip switches.

Body assembly has been one of the foremost operations to be automated, largely because much of it is repetitive in nature. Automated machinery can lift, position, hold, clamp, weld, check, inspect, diagnose and report on its own malfunctions. These functions can be performed without human intervention.

In body assembly, the floor pan, doors, front and roof of a car are assembled together and welded (Fig. 1). Because of the complexity of such a line, a large number of PLCs whose status is shown on control panels located along the assembly operations indicate the functioning/cycling and progress of assembly through the various stages. A malfunction at any stage can bring the entire line to a stop. In body framing methods which do not use a continuous line, such as that used by Fiat with Robogate, the effects of a malfunction may be more localised. However, assembly operations here also are complex enough to use a large number of PLCs for indication of status, progress and other operations.

The status and functioning of these automated operations for material movement, clamping, positioning, aligning, welding, checking and releasing must be monitored and shown by a number of detection and status indicators. Present technology is such that the status of each switch, each weld gun, and each clamp, for example, is displayed

Frame

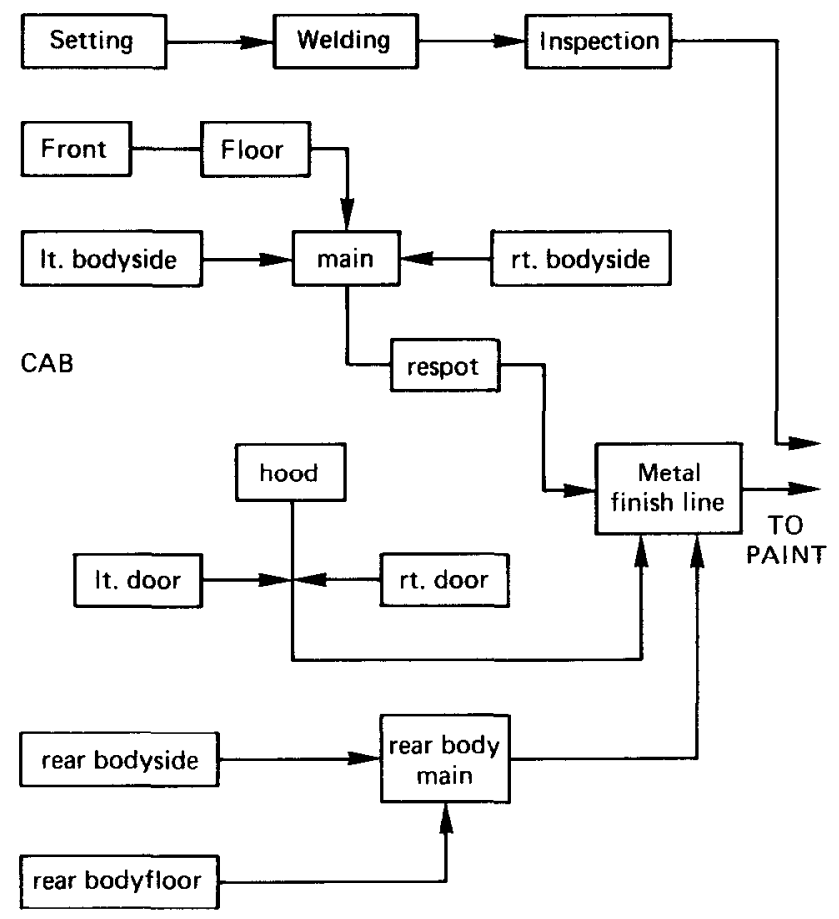

Fig. 1 Schematic of body automation on a console panel. Because of the large number of data points that must be indicated or 'broadcast', some panels have as many as $200-300$ display elements and several associated control switches. Unfortunately, fixture faults or other process faults are not self-correcting and the individual worker must look at the control panel to determine the nature and location of the fault, the seriousness of the fault and whether it is something that can be fixed readily or additional help would be required. Because these display/control panels are often the major source of information and the only point in the automated assembly line where a human frequently interacts with the line, they should be designed to be easily accessible. $\mathbf{A}$ quick glance should enable the worker to determine (1) the nature and location of the line problem, and (2) the correct course of action to take to rectify the problem. The latter may even include an emergency shut-down of the line. What makes the control panels unique is that no analogue meters are used or required, only on-off lamp indicators and the associated legend tags that must be quickly viewed to determine the location and nature of one or more faults on a stopped line.

When processes were not fully automated, these status and machine cycling performance display panels were small enough (with fewer than 30 to 35 discrete indicators) that deficiencies in their layout and design were probably not even noticed by the workers. It was reasoned that the display was not monitored continuously and the line operator could quickly become familiar with the panel layout and control locations. Besides, the worker could often see the actual malfunction. But this is not so easy now. Higher degrees of automation have created the need to display many more functions and status points.

Unfortunately, space is always limited and there are constraints in positioning the panels.

\section{Significance of displays design}

The design of PLC console displays is important for several reasons. First, well designed displays can be made more compact, therefore more cost and space efficient. Second, a display that shows a high degree of correspondence with the process that is being displayed, and permits easy access for ease of controllability, is perceived as being clean, imposing an acceptable level of workload on the worker. This means a reduction in the time required to search for and identify a line problem, determine the status of machine cycling, and access the desired control switch in an actual or perceived emergency. Ekkers et al (1979) regard the importance of well designed displays in automated processes as even more far reaching, and suggest that clarity and relevance of process information is associated with low levels of worker stress and with good health.

A third reason is that often the only indication of the nature of a line problem can be obtained from one or more control panels, and only one worker may be monitoring several panels on the line. The task of the worker can be made simpler if the display panels are well designed.

A fourth reason is that even though automation reduces the need for personnel, those on the job must be more skilled, more knowledgeable and more flexible to cover more than one automated line. Control panels and the interfaces they represent should be configured to permit flexible task assignment and rotation. 


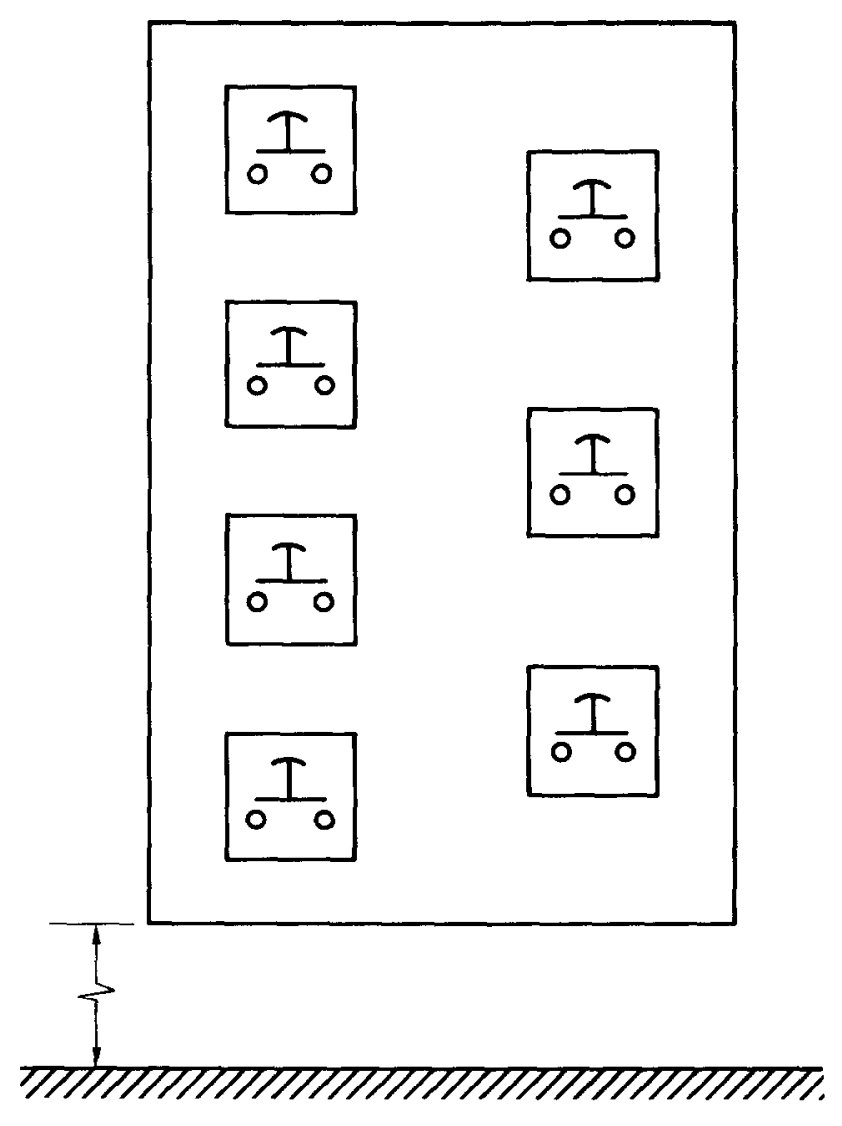

Fig. 2 Non-uniformity in location of emergency stop

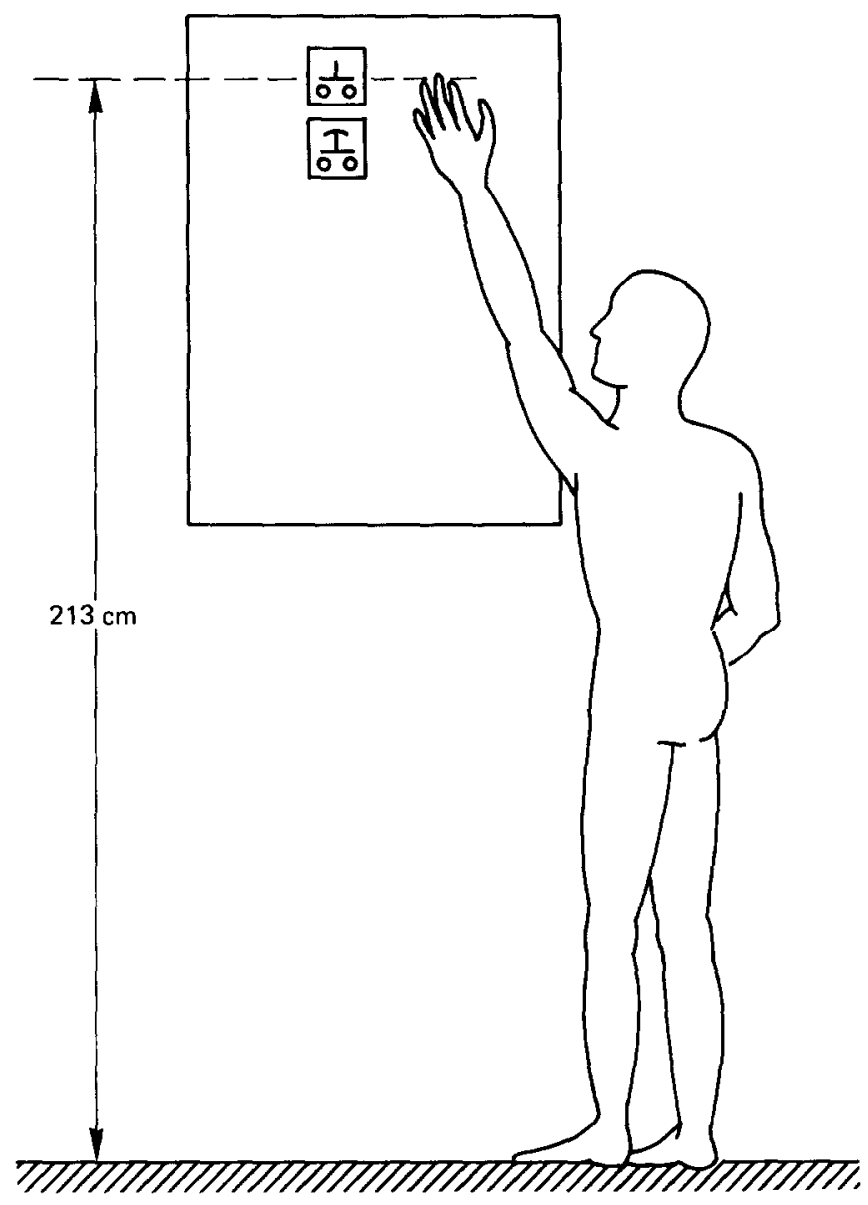

Fig. 3 Contröl inaccessibility
Perhaps the major reason for advocating that control panels in automated assembly operations be well designed is safety. Safety-critical alarm indicators and safety-critical or emergency switches must be located and designed in the context of the overall PLC in accord with human factors principles. As has been noted by others, human error that leads to an incident or accident is often caused by deficiencies in design or through inadequate training and procedures that are dictated by specific equipment designs (Seminara, 1976).

This paper discusses the practical difficulties of implementing human factors principles in the design of body assembly system displays and describes through examples how traditional designs and design procedures used within the industry were revised to reflect human factors guidelines.

\section{Some operational problems}

Different pieces of automation machinery, each with its own control panel, are often provided by different suppliers. Once on the shop floor, these pieces are brought together and integrated into the assembly line. There is a noticeable diversity in panel design and layout from supplier to supplier. Fig. 2 shows different locations of the standardised red mushroom shaped emergency stop (E-stop) button for different panels on the same line within the same plant!

Assembly plants are highly intricate and, at least for those that use long continuous assembly lines, space is often at a premium. As such the location of PLC door panels or
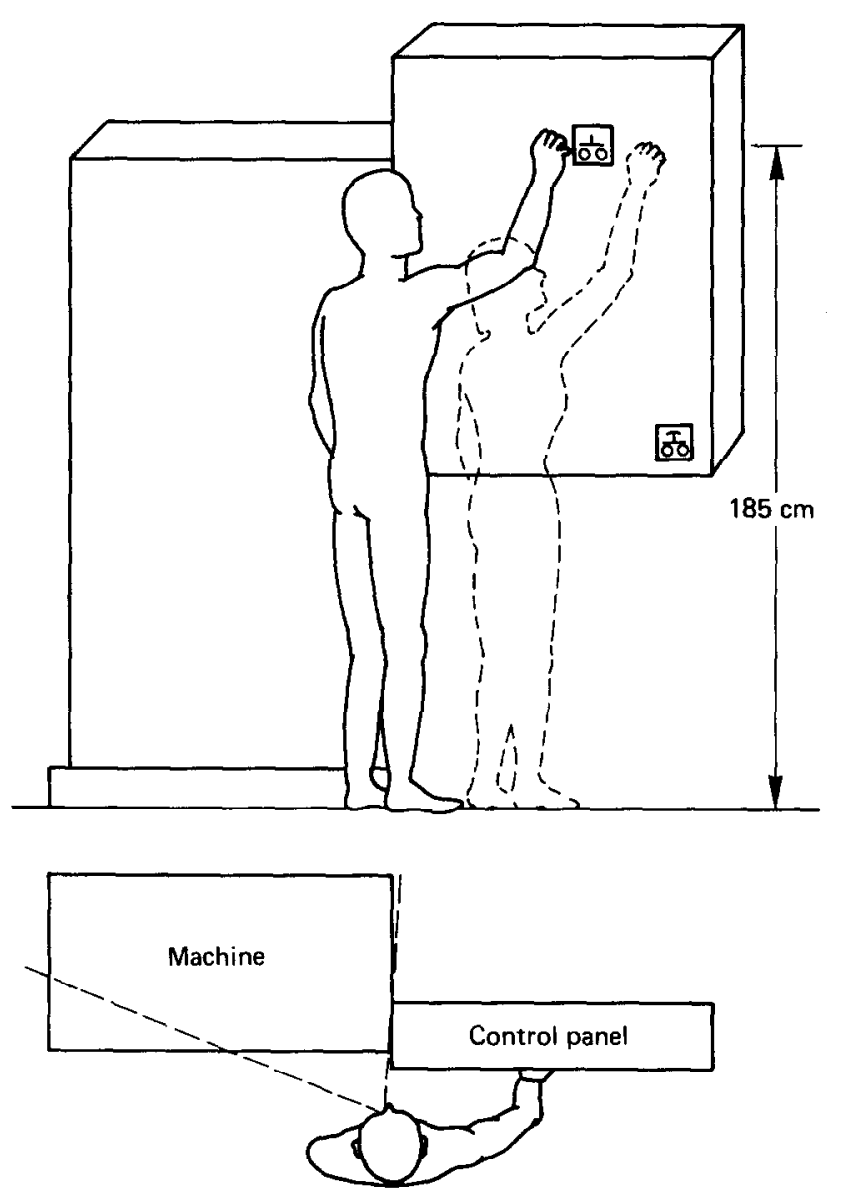

Fig. 4 Control accessibility and visual feedback 
unit controls along various fixtures is subject to space and height constraints.

Although it is desirable to locate a panel as close as possible to the machine unit to be controlled from it, and to provide the worker with a clear view of the process being controlled, such has often not been the case in highly intricate assembly plants. Panel location orientation may be such that the worker cannot simultaneously view the display, operate the control, and yet have a clear view of the process being controlled. When facing away from a view of the line, the worker is unable to see immediate results of his control action without awkwardly craning the neck or
Table 1: Significant criteria for panel design

1. Functional distinction

2. Sequential layout

3. Compatibility in location, movement and meaningfulness

4. Layout uniformity

5. Colour and other coding consistency

6. Conservation of panel space

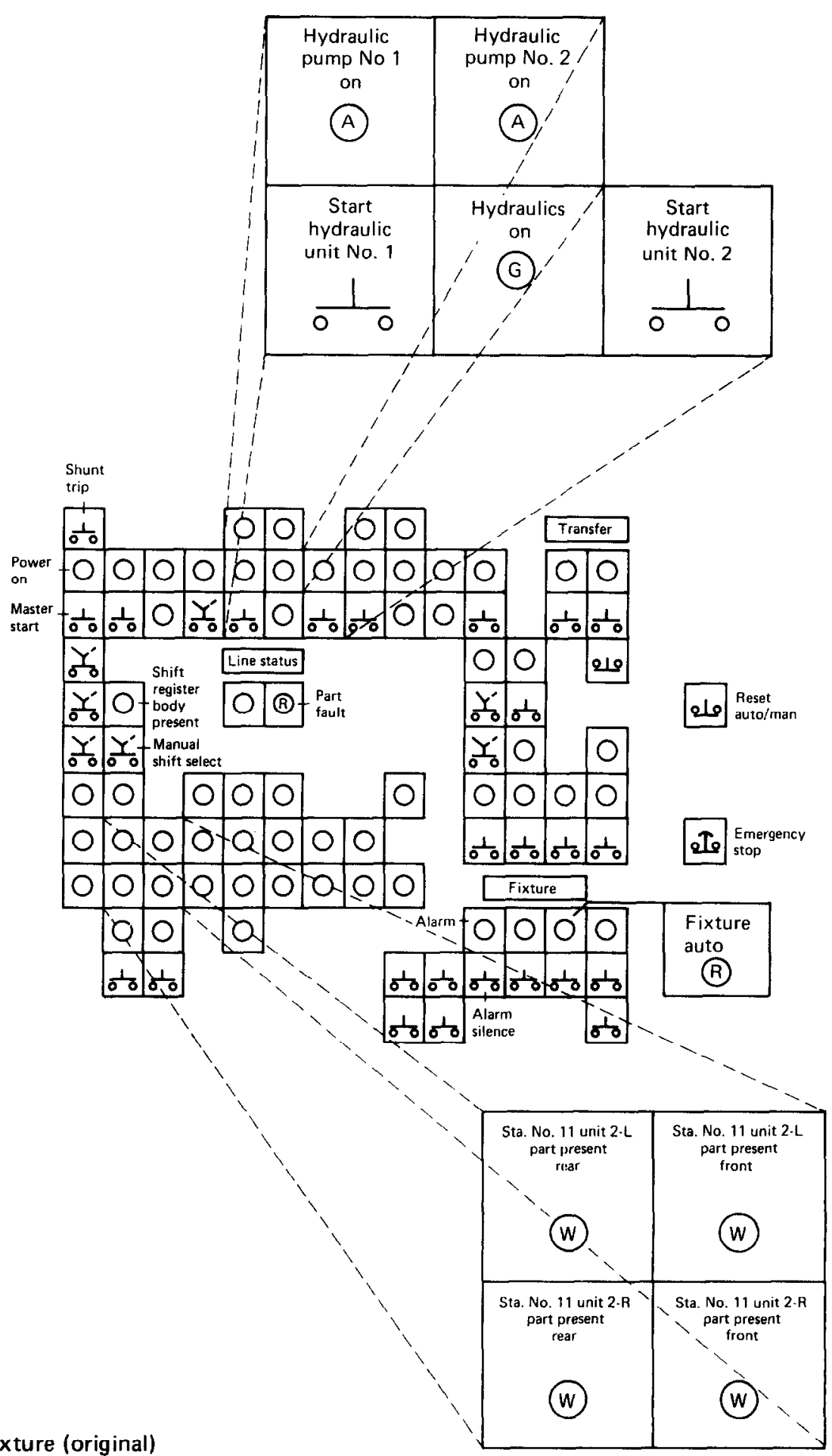

Fig. 5 Panel schematic for frame welding fixture (original) 
twisting the upper torso. This is especially true when a machine is slowly advanced through its steps for alignment or maintenance. The problem of location orientation can also have safety implications for maintenance and repairs.

Another common problem is control accessibility, especially for control and display panels that are specific to a machine tool, press or fixture. Different manufacturers use their own criteria and guidelines for control panel design and layout. This results in variability and, more of ten than not, controls that may not be accessible and display indicators that may not be easily visible to the worker in a normal working posture. In Fig. 3, for example, a manual switch $213 \mathrm{~cm}$ from the ground on the control panel of a dash panel press is at the fingertips of the stretched hand of the 59 th percentile male. Also, because of the elevated location of the panel, the legend tags of the upper indicator lamps cannot easily be seen. When the panel was lowered by $28 \mathrm{~cm}$, as shown in Fig. 4 , the switch height of $185 \mathrm{~cm}$ was easily reached by the 5 th percentile female.

\section{Criteria for PLC location, design and layout}

Of greater complexity are the design and layout of the control panels. The application and implementation of major human factors criteria, well documented in Applied Ergonomics Handbook (1974); Moore (1975); and Woodson (1981), and summarised in Table 1, reduce the time required to search, identify and locate an indicator of a machine malfunction problem. In recent applications of these criteria to automotive assembly, inputs were provided to the design shops when proposed designs were still on paper.

One example comes from the body framing fixture used for welding the automobile body before it is painted. The operation is fully automatic. Each of four major steps carried out at this point is indicated by a separate PLC panel: (1) start and set-up conditions, (2) parts clamping, (3) indexing and weld gun positioning, and (4) weld sequence completion, indexing and unclamping. For simplicity, only select aspects of the display are chosen for this example.

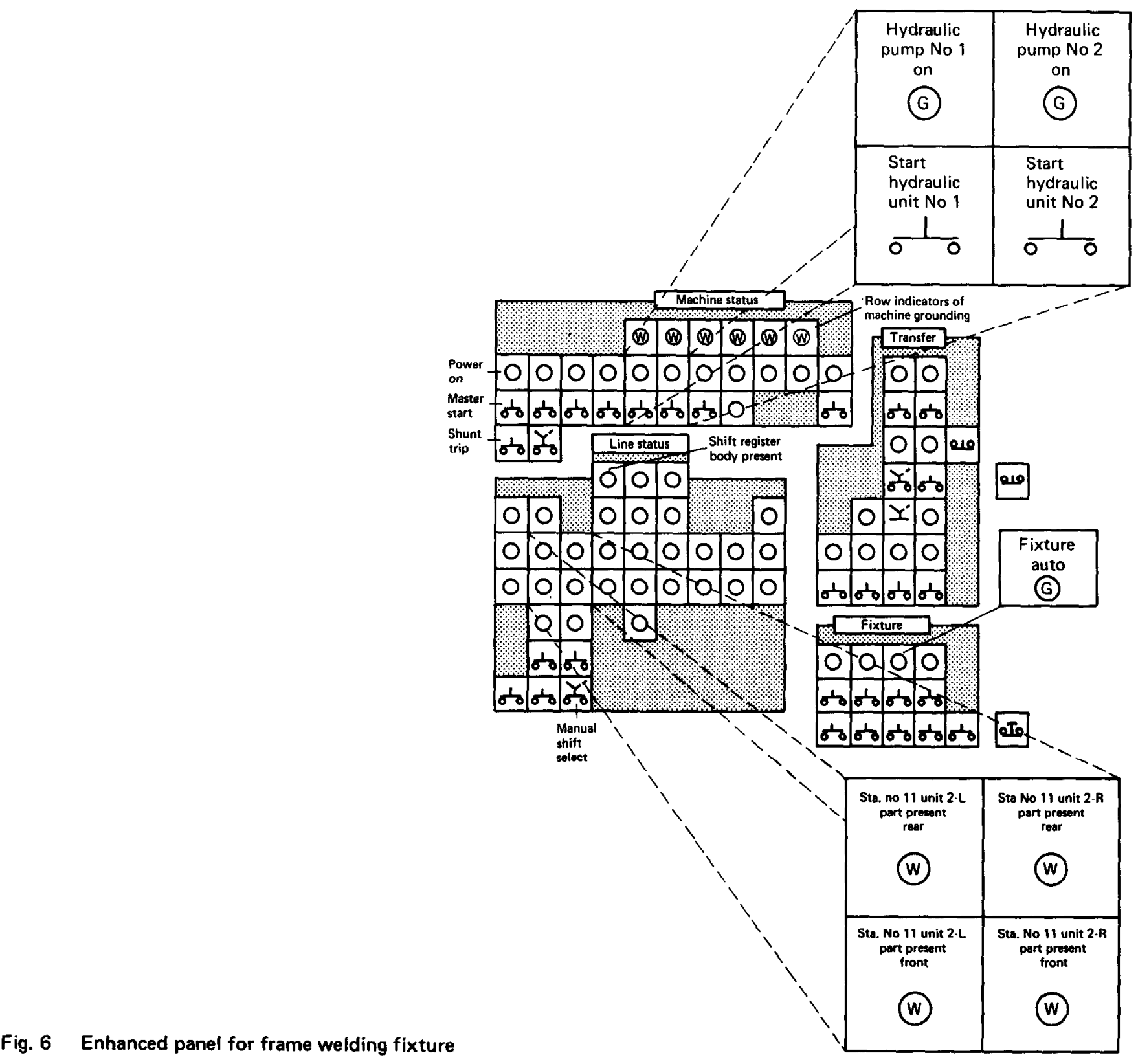




\section{Functional distinction}

Fig. 5 represents the layout of a control panel originally proposed to show the status of 'start and set-up' for an automobile frame welding fixture. Four distinct subsets of machine functions were to be controlled and displayed by this panel: status of the machine itself, status of the line, status of transfer unit, and status of fixture. Yet none of the functional groups was readily distinct from the others and it was unclear where the beginning and end points for each group were located. This could have resulted in some confusion for the inexperienced worker. Fig. 6 shows the improved design with functional demarcation of the various groups through a combination of borders and panel enhancement. Each indicator is clearly identified with a subgroup.

For efficiency in manufacture of the panels, each indicator lamp and control switch location was placed on $4.45 \mathrm{~cm}$ centres, this distance being determined by the space requirements of the solenoid mount behind each lamp. Thus with a $0.55 \mathrm{~cm}$ diameter lamp, there is ample room for the legend associated with each indicator to be displayed above the lamp or switch. Lamps and control switches are positioned in rows and columns in a matrix This matrix approach to location is desirable because additions or changes can easily be made should additional processes be added to the line.

In another form of functional distinction, rather than distribute 'fault' indicator lamps across the panel, it was more appropriate to show that they were functionally unique and to give them a specific area of the panel, such as the top one or two rows for machine status or fault indication (Figs. 6, 8 and 10).

\section{Layout by sequence}

It has been industry practice to design an indicator panel so the sequence of events is from left to right and from top to bottom - i e, indicator lamps and switches on the left represent processes that precede those on the right. A similar sequential logic applies to those positioned top to bottom. To illustrate, Fig. 7 shows the PLC for a fully automatic machine to set and adjust the toe-in and toe-out for the front axle and wheel assembly. When the machine is set for manual operation, the sequence in which the various switches are activated is traced by the arrow diagram. An improved sequence which is orderly and sequential is shown in Fig. 8.

\section{Compatibility}

Once functionally related indicators have been grouped together, each subgroup should be designed so the physical arrangement of the indicators and controls and the codes and colours used for the lamp indicators follow the guidelines of 'location', 'movement' and 'meaningfulness' compatibility. The rationale behind compatible relationships is to make the PLC layout consistent with human expectations.

\section{Location compatibility}

In its simplest form, location compatibility between a display indicator and its associated control means positioning these contiguously, with the control switch located beneath its associated display. A violation of this guideline is illustrated in Fig. 5 where the activation of 'START

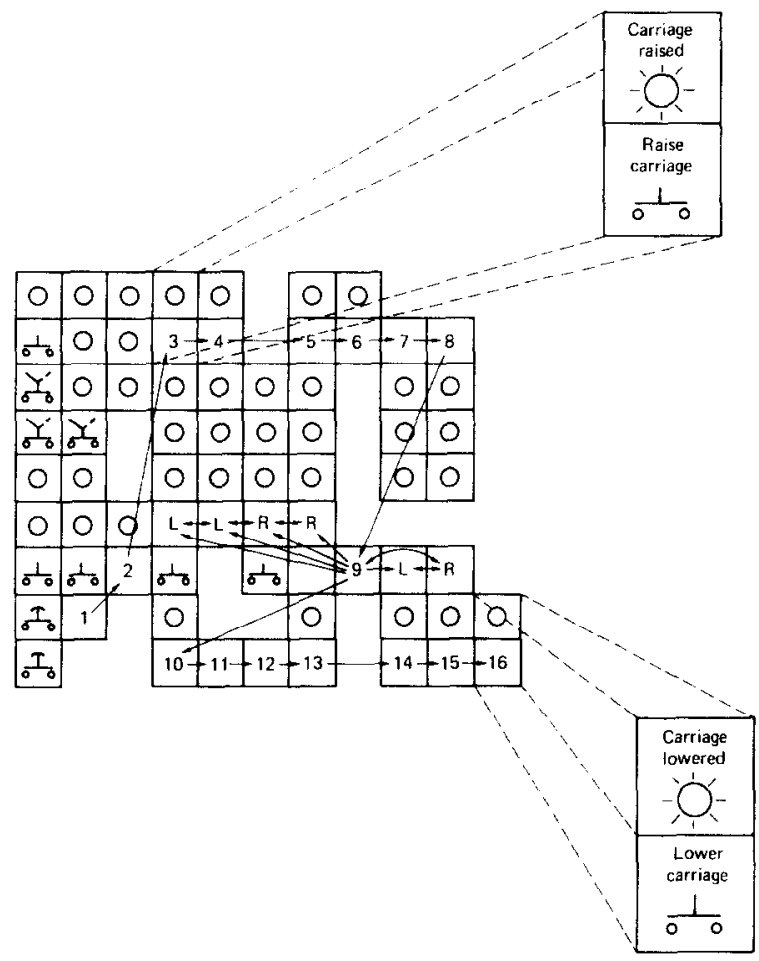

Fig. 7 Panel schematic for toe adjust machine (original)

IIYDRAULIC UNIT \#2' switch in the Machine Status section results in a positive indication (a green lamp lights up) to its left and above showing that 'HYDRAULIC PUMP \#2 (is) ON'. In the revised design the switch was positioned directly below the indicator, as shown in Fig. 6. This then resembled the locational relationship of HYDRAULIC UNIT \#1.

In a second form of locational incompatibility, a display is positioned contiguous to an unrelated control. In the design in Fig. 5, the activation of 'MANUAL SHIFT SELECT' was not related to the indication lamp (i e, SHIFT REGISTER BODY PRESENT) directly above it. For locational compatibility, the 'SHIFT REGISTER BODY PRESENT' lamp indication was shifted and grouped with

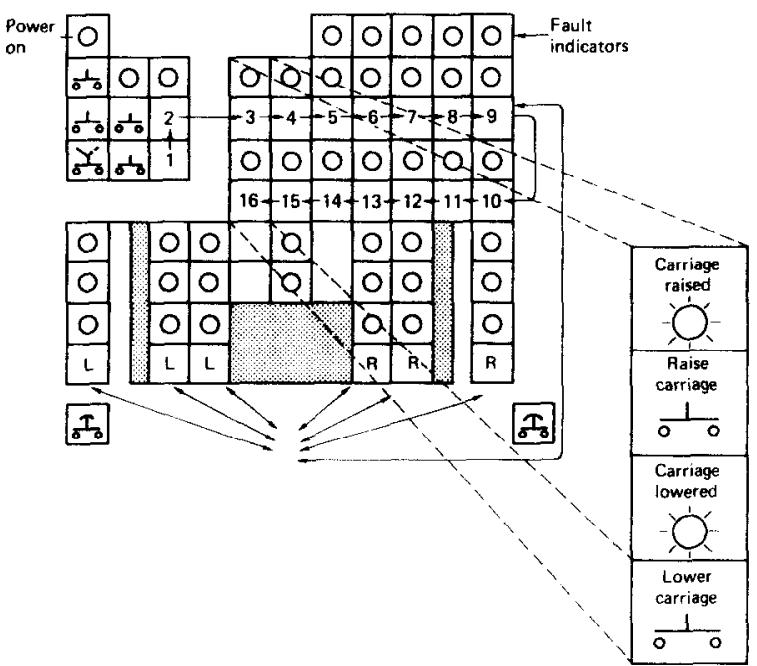

Fig. 8 Revised panel for toe adjust 
other indicators for 'LINE STATUS' that did not require an associated control (Fig. 6) and the 'MANUAL SHIFT SELECT' switch was moved to the bottom row.

Not only should associated controls and displays be vertically contiguous, but other control/display pairs that perform a similar function should be next to each other. In Fig. 7, each pair of indicators and switches for raising and lowering the carriage is compatible but the pairs are widely separated. In the redesign in Fig. 8, the pairs adjoin each other vertically, that for lowering being placed appropriately below that for raising.

\section{Movement compatibility}

As conventionally understood, movement compatibility refers to maintaining directional fidelity between the direction in which a control switch is thrown and the direction of movement of the indicator of the controlled process. However, PLC designs do not use throw switches and thus directional compatibility does not become relevant.

\begin{tabular}{|c|c|}
\hline $\begin{array}{c}\text { Unit No 4 } \\
\text { front header } \\
\text { to } \\
\text { bodyside }\end{array}$ & $\begin{array}{c}\text { Unit No 13 } \\
\text { front roof bow } \\
\text { to } \\
\text { bodyside }\end{array}$ \\
\hline
\end{tabular}

\begin{tabular}{|c|c|c|}
\hline $\begin{array}{c}\text { Unit 4-L } \\
\text { G1 back-up } \\
\text { ret. }\end{array}$ & $\begin{array}{c}\text { Unit 13-L } \\
\text { G1 back-up } \\
\text { ret. }\end{array}$ & $\begin{array}{c}\text { Unit 13-L } \\
\text { G1 back-up } \\
\text { ret. }\end{array}$ \\
\hline G & G & G \\
\hline $\begin{array}{c}\text { Unit 4-R } \\
\text { G1 back-up } \\
\text { ret. }\end{array}$ & $\begin{array}{c}\text { Unit 13-R } \\
\text { G1 back-up } \\
\text { ret. }\end{array}$ & $\begin{array}{c}\text { Unit 13-R } \\
\text { G1 back-up } \\
\text { ret. }\end{array}$ \\
W & W & W \\
\hline $\begin{array}{c}\text { Unit 4-L } \\
\text { back-up } \\
\text { advd. }\end{array}$ & $\begin{array}{c}\text { G1 back-up } \\
\text { advd. }\end{array}$ & $\begin{array}{c}\text { G1 back-up } \\
\text { advd. }\end{array}$ \\
A & A & A \\
\hline $\begin{array}{c}\text { Unit 4-R } \\
\text { G1 back-up } \\
\text { advd. }\end{array}$ & $\begin{array}{c}\text { G1 back-up } \\
\text { advd. }\end{array}$ & $\begin{array}{c}\text { G1 back-up } \\
\text { advd. }\end{array}$ \\
W W & W & W \\
\hline
\end{tabular}

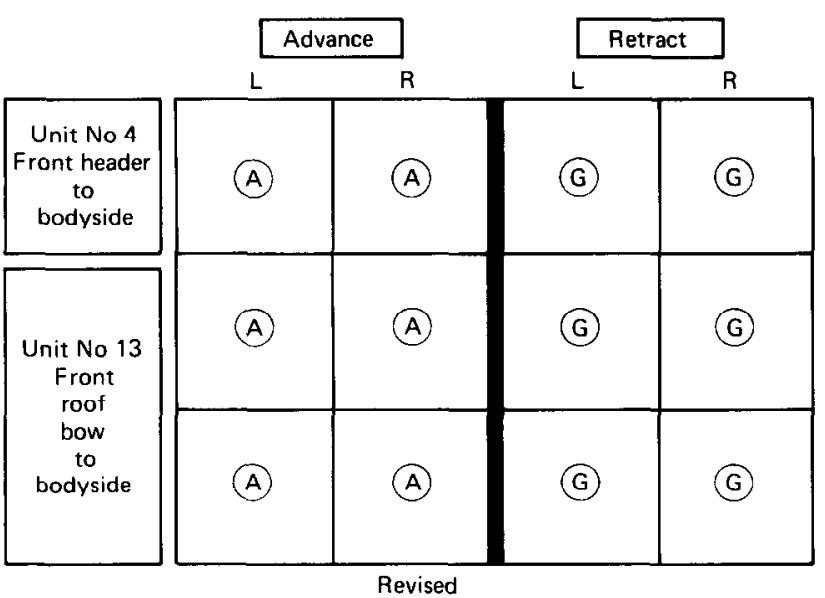

Fig. 9 Layout, colour and coding consistency
Sernantic compatibility

Semantic or 'meaningfulness' compatibility refers to an implied or acquired understanding of the logical relationship between a display and its meaning. For example, one undesirable consequence of industry practice of designing indicator panels so the sequential progression of assembly is displayed from left to right and top to bottom is reflected in Fig. 5. For Station \#11 (STA\#11), 'PART PRESENT' indication for UNITs 2-L and 2-R is such that left $(L)$ is not on the left and right (R) is not on the right. Part present detection first occurs at the rear section of the auto frame, both for left and right units at Station $\# 11$, and then at the front. Semantically, left is to the left of right, and front precedes rear. As such, to maintain semantic compatibility as to location on the control panel so that left, right, front and rear are schematically compatible with their actual location, a revision was made to the arrangement. This revision, shown in Fig. 6, also conforms to industrial practice of indicating assembly progress from left to right and top to bottom.

One effect of maintaining geographical integrity in display layout is to reduce the time required to process information. By also making it unnecessary to label a group of related elements of the display with identically sized and highly repetitive letters, a more compact design results that also requires less space. Fig. 9 shows both the original and modified versions of a subset of the control panel. Another example of this is shown in Fig. 8 where the left and right indication of toe-in and toe-out adjustment is on the corresponding side of the PLC.

\section{Layout uniformity}

In its simplest form, this refers to uniformity of layout between all functionally similar panels. Further, all essential and/or safety-critical indicators and controls should be identically located from one panel to the next, as in the revised location of the mushroom shaped E-stop which is in the bottom right-hand corner of each panel.

\section{Colour and other coding consistency}

The practice on the assembly line has been to use red, green, amber, white and blue lamps for status indication; but if functional separation and compatibility are not considered in PLC layout, then the use of different coloured lamps can impart a 'Christmas tree' effect and lead to confusion and delay in fault location and determination.

For example, a red lamp is semantically associated with a fault, an error, or 'stop' situation. Some deviations apply within the power industry in that normal machine-ON (machine in energised state) is reflected by a lit-up red pilot lamp. To maintain this uniqueness of the power-ON red lamp it should be geometrically and visually separated from other red coloured indicators - for example, by locating the pilot lamps in a designated periphery of the PLC (Fig. 8).

All normal flow conditions, such as 'HYDRAULIC PUMP ON', etc, are indicated in green. Green is also semantically representative of a 'normal' state of operation of automated machinery in the 'auto' mode; only during start-up or maintenance does the machine or unit enter the 'non-normal' mode. Generally, the 'non-normal' mode is also the 'manual' mode. As such, any indication of 'auto' mode should be reflected by a 'green' lamp (Figs. 5 and 6). 
In part clamping (a part once clamped is presumed ready for welding) and unclamping, an 'UNCLAMPED' situation represents the 'normal' machine position; as such, it is indicated in green. This unclamped situation is synonymous with the clamping hooks in the 'retracted', 'returned' or 'home' position. Conversely, the 'CLAMPED' position is synonymous with the clamping hooks being 'advanced'. Industry practice has been to use an amber coloured lamp to represent the ADVANCE position for parts clamping. A misapplication of this code arises when both Left and Right side units need to be indicated as being either 'ADVANCED' or 'RETRACTED'. Fig. 9 (original) is an example taken from an original PLC layout. The ADVD (advance) position is indicated by amber and white lamps, amber for the left (L) units and white for the right (R) units; the RET (return) position is indicated by green and white lamps, green for the left and white for the right units. Thus a white lamp is used to indicate both an ADVD and a RET position, which clearly are two contrary situations. This violates the principle of colour code consistency. To maintain consistency, amber and green were selected to represent 'ADVANCE' and 'RETRACT' which are indications of location of machine units, as in the revision shown in Fig. 9.

Colour coding was also improved by using a white lamp to indicate grounding conditions (Fig. 6). The representation of grounding conditions is of machine states rather than of parts or materials movement. The grounding condition lamps, like other 'state indication' lamps, are best positioned in the periphery of the layout, such as in the top row.
White lamps are also used to indicate other machine states, such as the presence of a 'part' or 'body' at specific points in the assembly process.

In design improvements, the use of multiple colours on a display was discouraged because colour then loses its uniqueness. The adequacy of the coolant pressure for welding guns, 'GUN PRESSURE', has in the past been indicated by blue lamps (Fig. 10). However, blue is semantically associated with situations which imply marginal conditions, where equipment should not be started or moved (Woodson, 1981). Since these lamps indicate status, the proper and consistent colour should be white, rather than blue. Further, as gun pressure indication lamps are unique and functionally distinct from other lamps on the control panel, they are better separated by a border rather than by a special colour (Fig. 11).

\section{Conservation of panel space}

One major objective has been to design the PLC concisely and succinctly to conserve panel space. Often, this also has led to a PLC design that is easily comprehensible. For example, Fig. 10 shows an existing layout of the top half of a weld sequence indication panel. The most significant part of this display is the set of weld completion lamps in the left vertical column. These indicators light up as the welding sequence progresses from the 1st WELD through 11 th WELD. In the event of a problem in the welding sequence, the last lit lamp provides an indication of where to search for possible faults. The

Fig. 10 Weld sequence indication panel

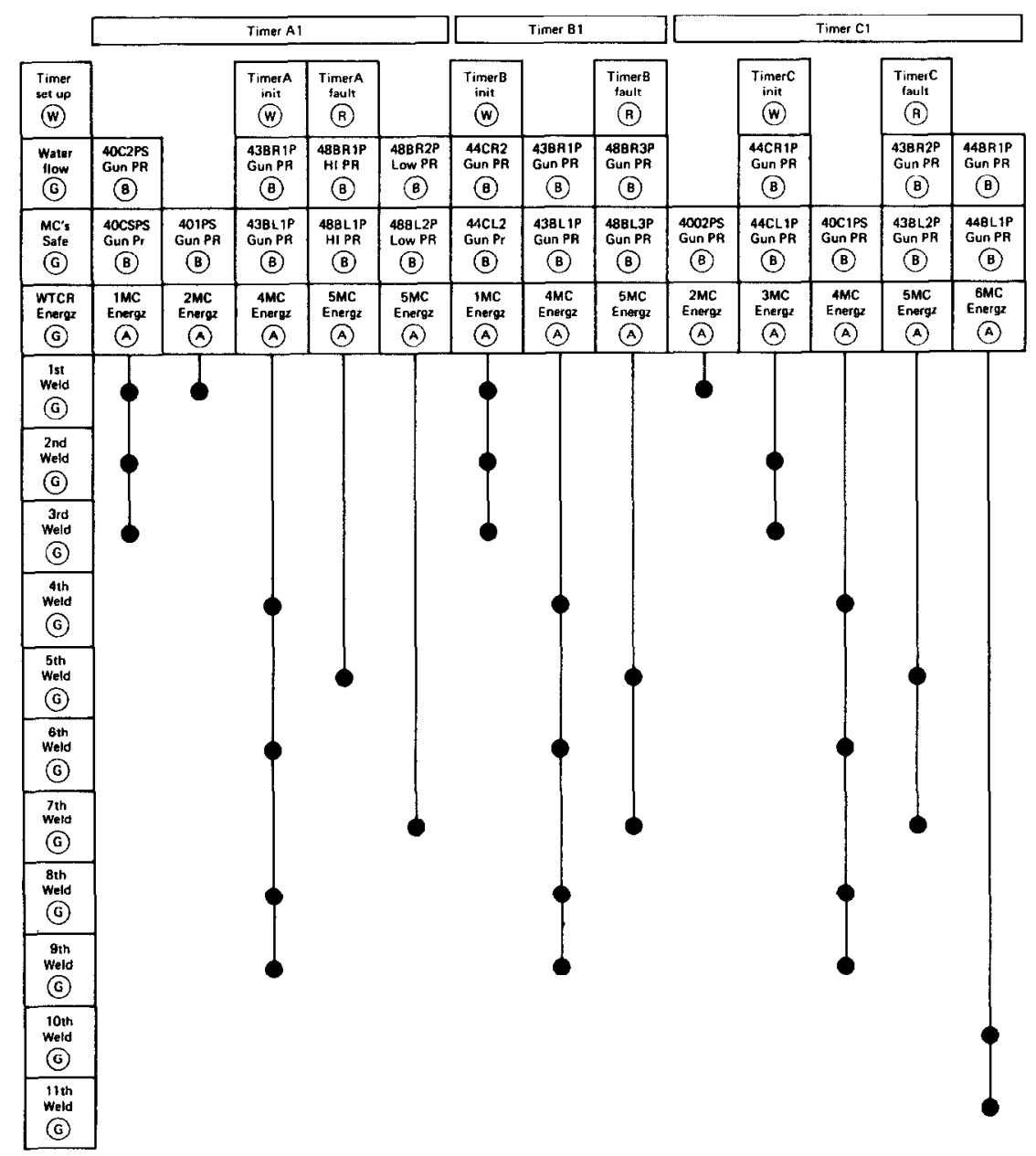




\begin{tabular}{|c|c|c|c|c|c|c|c|c|c|c|c|c|c|}
\hline \multirow[b]{2}{*}{$\begin{array}{c}\text { Timer } \\
\text { set up } \\
\text { W }\end{array}$} & \multicolumn{5}{|c|}{ Timer A1 } & \multicolumn{3}{|c|}{ Timer $\mathbf{8} \mathbf{1}$} & \multicolumn{5}{|c|}{ Timer $\mathrm{Cl}$} \\
\hline & & & $\begin{array}{c}\text { TimerA } A \\
\text { init } \\
(W)\end{array}$ & $\begin{array}{c}\text { TimerA } \\
\text { fault } \\
\text { B }\end{array}$ & & $\begin{array}{c}\text { TimerB } \\
\text { inis } \\
(W)\end{array}$ & & $\begin{array}{c}\text { TimerB B } \\
\text { fault } \\
\text { B }\end{array}$ & & $\begin{array}{c}\text { Timerc } \\
\text { init } \\
(W\end{array}$ & & $\begin{array}{c}\text { Timerc } \\
\text { fault } \\
\text { (B) }\end{array}$ & \\
\hline $\begin{array}{c}\text { Water } \\
\text { flow } \\
\text { (G) }\end{array}$ & $\begin{array}{c}\text { 40C2PS } \\
\text { Gun PR } \\
\text { (W) }\end{array}$ & & $\begin{array}{c}\text { 43BR 1P } \\
\text { Gun PR } \\
\text { (W) }\end{array}$ & $\begin{array}{c}\text { ABBR1P } \\
\text { HIPR } \\
\text { (W) }\end{array}$ & $\begin{array}{l}\text { 48BR2P } \\
\text { Low PA } \\
\text { (W) }\end{array}$ & $\begin{array}{c}44 C R 2 \\
\text { Gun PR } \\
\text { (W) }\end{array}$ & $\begin{array}{c}\text { 43BR 1P } \\
\text { Gun PR } \\
\text { (W) }\end{array}$ & $\begin{array}{c}\text { 48BR3P } \\
\text { Gun PR } \\
\text { (W }\end{array}$ & & $\begin{array}{c}\text { 44CR1P } \\
\text { Gun PR } \\
\text { (W) }\end{array}$ & & $\begin{array}{c}\text { 43BR2P } \\
\text { Gun PR } \\
\text { (W) }\end{array}$ & $\begin{array}{l}\text { 44BR 1P } \\
\text { Gun PPR } \\
\text { (W) }\end{array}$ \\
\hline $\begin{array}{l}\text { MC's } \\
\text { sale } \\
\text { (G) }\end{array}$ & $\begin{array}{c}\text { 40CSPS } \\
\text { Gun PR } \\
\text { (W) }\end{array}$ & $\begin{array}{c}\text { 401PS } \\
\text { Gun PR } \\
(W)\end{array}$ & $\begin{array}{c}\text { 43BL } 1 P \\
\text { Gun Pr } \\
\text { W }\end{array}$ & $\begin{array}{c}48 B L 1 P \\
H I P R \\
(W\end{array}$ & $\begin{array}{c}\text { 48BL2P } \\
\text { Low PR } \\
\text { (W) }\end{array}$ & $\begin{array}{c}44 C L 2 \\
\text { Gun } P A \\
\text { (W }\end{array}$ & $\begin{array}{l}\text { 43DL1P } \\
\text { Gun PR } \\
\text { (W }\end{array}$ & $\begin{array}{c}\text { 48BL3P } \\
\text { Gun PR } \\
\text { (W) }\end{array}$ & $\begin{array}{c}\text { 40D2PS } \\
\text { Gun PR } \\
\text { (W) }\end{array}$ & $\begin{array}{c}\text { A4CL IP } \\
\text { Gun PR } \\
\text { (W) }\end{array}$ & $\begin{array}{c}40 C_{1} P S \\
\text { Gun PR } \\
\text { (W) }\end{array}$ & $\begin{array}{c}\text { 43B L2P } \\
\text { Gun PR } \\
\text { (W) }\end{array}$ & $\begin{array}{c}\text { A4BL1P } \\
\text { Gun PR } \\
\text { (W) }\end{array}$ \\
\hline $\begin{array}{l}\text { WTCR } \\
\text { Energz } \\
\text { (G) }\end{array}$ & $\begin{array}{c}1 \mathrm{MC} \\
\text { Energz } \\
\text { (A) }\end{array}$ & $\begin{array}{c}2 M C \\
\text { Energz } \\
\text { (A) }\end{array}$ & $\begin{array}{c}\text { 4MC } \\
\text { Energz } \\
\text { (A) }\end{array}$ & $\begin{array}{c}\text { 5MC } \\
\text { Energz } \\
\text { (A) }\end{array}$ & $\begin{array}{c}5 M C \\
\text { Energz } \\
\text { (A) }\end{array}$ & $\begin{array}{c}1 \mathrm{MC} \\
\text { Energz } \\
\text { (A) }\end{array}$ & $\begin{array}{c}4 M C \\
\text { Energz } \\
\text { (A) }\end{array}$ & $\begin{array}{c}5 M C \\
\text { Energz } \\
\text { (A) }\end{array}$ & $\begin{array}{c}\text { 2MC } \\
\text { Energz } \\
\text { (A) }\end{array}$ & $\begin{array}{c}\text { 3MC } \\
\text { Energz } \\
\text { (A) }\end{array}$ & $\begin{array}{c}\text { 4MC } \\
\text { Energz } \\
\text { (A) }\end{array}$ & $\begin{array}{c}5 M C \\
\text { Energz } \\
\text { (A) }\end{array}$ & $\begin{array}{c}\text { 6MC } \\
\text { Energz } \\
\text { (A) }\end{array}$ \\
\hline & & & & & & & & & & & & & \\
\hline
\end{tabular}

Fig. 11 Revised weld sequence indication panel

worker performs a visual check of the status, as marked by plastic streamers and coloured plastic dots glued to the door panel. For example, if the 3rd WELD is the first unlit lamp, then a horizontal search shows that the problem could be in any or all of the three Timers A1 (40C2PS GUN PR, 40CSPS GUN PR, 1MC ENERGZ), B1 (TIMERB INIT, 44CR2 GUN PR, 44CL2 GUN PR, 1MC ENERGZ) or C1 (TIMERC INIT, 44CRIP GUN PR, 44 CLIP GUN·PR, 3MC ENERGZ).

If the first nine lamps are lit and the 10th WELD completion lamp is unlit and the welding process has stopped, then the problem could only be in Timer $\mathrm{Cl}$ (44BRIP GUN PR, 44 BLIP GUN PR, and/or 6MC ENERGZ).

This method of displaying correlating information is both time consuming and leads to errors. The revised door panel utilised an LED to display the 11 weld completions and a set of pointer arrows to indicate the column to be searched for possible error (Fig. 11).

\section{Conclusions}

As automation increases, the need to provide timely and accurate information to the worker becomes more and more important. Automobile body assembly can be greatly facilitated by clear, concise and well designed displays. As many a human factors practitioner may have discovered, long-established industry traditions and engineering practices are not always easy to change. In the case of PLC panels which were inexpensive to make and did the job adequately, there apparently was no urgent need for an ergonomic design. But the car industry is becoming aware of the fact that using ergonomics/human factors principles to design machine control displays in the shop, production and assembly areas makes the job of the worker much easier.

The recommended changes as indicated in the foregoing examples were accepted for implementation in the assembly plants of Ford Motor Company. The suggested revisions to the method of designing were acceptable to the engineers. Subjective comments from workers on the floor provided feedback that the new panels were effective in reducing confusion and indecision. An example of a completed and installed panel is shown in Fig. 12.

Some recommendations were not accepted because of difficulties in implementation. For example, the suggestion that panels be made wider rather than taller to enhance visibility of legend tags was not implementable because of

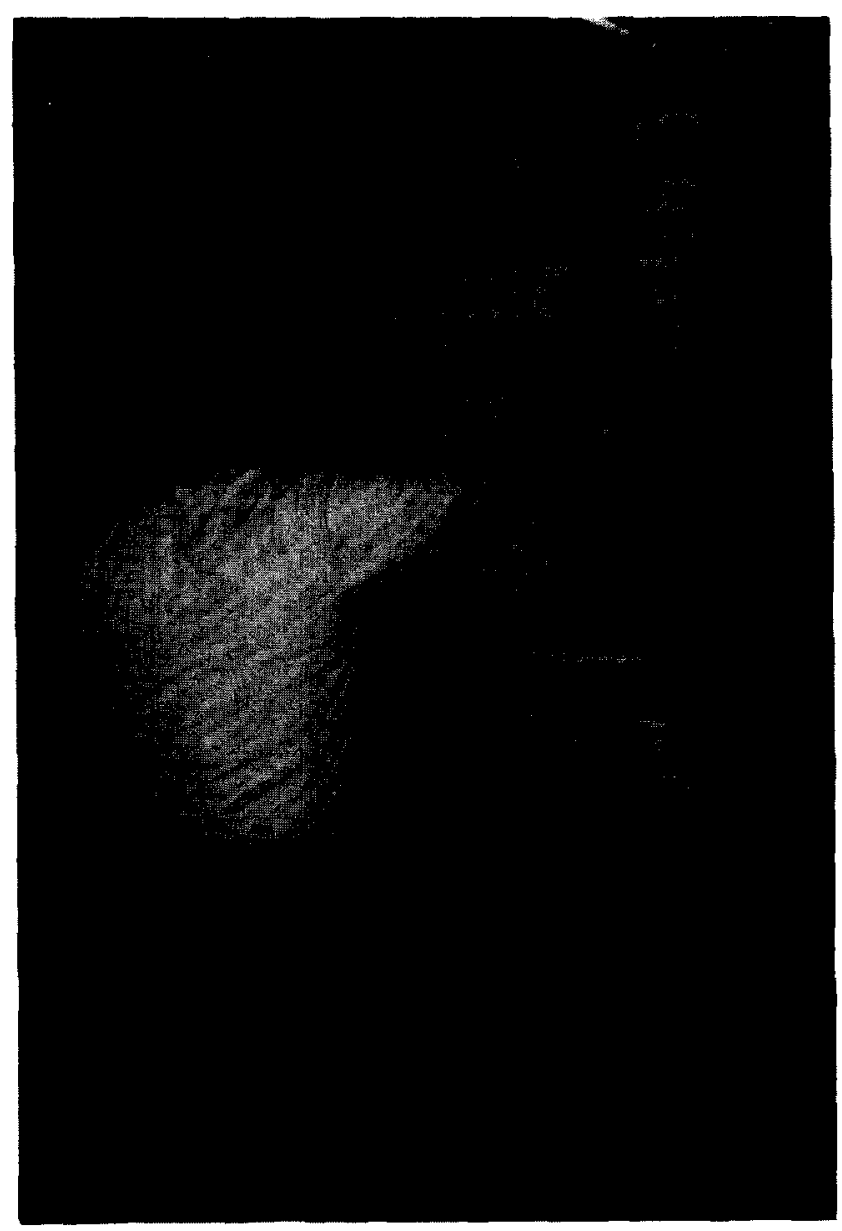

Fig. 12 A redesigned and operational PLC panel 
limitations of space around machinery. The suggestion that repetitive tag legends not be used in order to avoid clutter was unacceptable because it restricted flexibility for addons. The more radical suggestion, that alternative display methods such as those that use a CRT with graphic displays and a touch screen or keyboard for control operation be investigated, was not free of cost and reliability considerations.

In order to increase awareness of human factors and to encourage its applications to design, a series of educational seminars was conducted for the company and the numerous independent vendors who manufactured and supplied control panels. The results of these efforts are beginning to achieve fruition.

\section{Acknowledgement}

The preparation of this manuscript was supported by a grant from the Ford Motor Company, Body and Assembly Operations, Dearborn, Michigan. I am indebted to Dr McIlvain Parsons for useful comments on the original draft of this paper.

\section{References}

\section{Applied Ergonomics Handbook}

1974 Guildford, UK: IPC Science \& Technology Press.

Bainbridge, $L$.

1983 Ironies of automation. In: Analysis, design \& evaluation of man-machine systems. G. Johannsen and J.E. Rijnsdrop (Eds), pp 129-135. Pergamon Press, New York.
Ekkers, C.L., Pasmooij, C.K., Brouwers, A.F., and Janusch, A.J.

1979 Human control tasks. A comparative study in different man-machine systems. In: Case studies in automation related to humanization of work. J.E. Rijnsdrop (Ed), pp 23-29. Pergamon Press, New York.

Margulies, F., and Zemanek, $\mathrm{H}$.

1983 Man's role in man-machine systems. In: Analysis design and evaluation of man-machine systems. G. Johannsen and J.E. Rijnsdrop (Eds), pp 121-128. Pergamon Press, New York.

Moore, T.G.

1975 Applied Ergonomics, 6.1, 33-38. Industrial push buttons.

Rasmussen, $\mathbf{J}$.

1983 IEEE Transactions on Systems, Man and Cybernetics, SMC-13.3, 257-266. Skills, rules and knowledge; signals, signs and symbols, and other distinctions in human performance models.

Seminara, J.L.

1976 Human factors review of nuclear power plant control room design. Report No EPRI NP-309 S 4 project 501 . Palo Alto, CA: EPRI.

Woodson, W.E.

1981 Human factors design handbook. McGraw-Hill, New York. 